\title{
Low back injuries related to nursing professionals working conditions: a systematic review ${ }^{1}$
}

\author{
Roberta Schlossmacher ${ }^{\mathrm{a},}{ }^{*}$ and Fernando Gonçalves Amaral ${ }^{\mathrm{b}}$ \\ ${ }^{a}$ Physiotherapist, MSc in Production Engineering on UFRGS. Porto Alegre (RS), Brazil. \\ ${ }^{\mathrm{b}} \mathrm{PhD}$ in Ergonomics, Professor in PPGEP / UFRGS. Porto Alegre (RS), Brazil.
}

\begin{abstract}
Objective: Identify the prevalence of low back disorders and associated risks, as well as the characteristics and ergonomic factors present in the work of nursing professionals. Methods: Systematic review based on the search of terms such as low back pain, professionals, hospital ergonomics, work organization, nursing found in national and international databases. Results: The prevalence of low back pain symptoms was between $14.7 \%$ and $72 \%$ and the main cause, that is, the transference of the patient from bed to chair, leaded to the profession abandonment as a main consequence. Conclusion: it was possible to conclude that the prevalence of low back injury is high among nursing professionals and its causes are related to occupational factors - physical or psychological, which are in many cases permanent and disabling.
\end{abstract}

Keywords: low back pain, ergonomics, hospitals, work, nursing

\section{Literature Review}

Nurses are exposed to many procedures that pose accidents and diseases risks to the workers [1]. There are various occupational risks during exercise work, and talking care of the patient is the most arduous task. These risks can be classified as chemical, physical, biological, psychosocial and ergonomic [1,2]. Concerning the ergonomic risks, they are related to characteristics of jobs and positions taken, as well as forces, repetitive gestures and movements of nurses. In this context, the ergonomic factors are those that will directly affect the relationship between work and worker [3]. For nursing professionals $\mathrm{X}$ these risks are lifting load (patient), poor access to materials, the imposition of unfavorable postures in the biomechanical point of view, excess of demand of work, psychological factors, etc. [3, 4, 5]. Ergonomic conditions of nursing professionals' daily activities are related to the characteristics of the occurrence of low back pain [3].

\section{Methodological Formulation}

A systematic literature review based on the concepts developed by Sampaio and Mancini, 2007 [6] was done. The revision was based on the search of terms such as low back pain in nurses, hospital ergonomics, work organization, nursing, low back pain in nursing found on databases such as Google Scholar, PubMed and Scielo Brazil. From that search carried out by two researchers, 36 studies were classified as original articles and literature review. From reading the summary, 16 studies were selected because they showed the prevalence and characteristics of lumbar back injuries caused by unfavorable conditions of the work of nursing.

\footnotetext{
${ }^{1}$ Work done in Graduate Program in Production Engineering (PPGEP), Federal University of Rio Grande do Sul (UFRGS), Porto Alegre (RS), Brazil.

Roberta Slochnacher. E-mail: fisio.robertas@gmail.com.
} 


\section{Results}

The prevalence of low back pain symptoms was between $14.7 \%$ and $72 \%$ (figure 1) and the main cause, that is, the transference of the patient from bed to chair (figure 2), leaded to the profession abandonment as a main consequence(figure 3 )

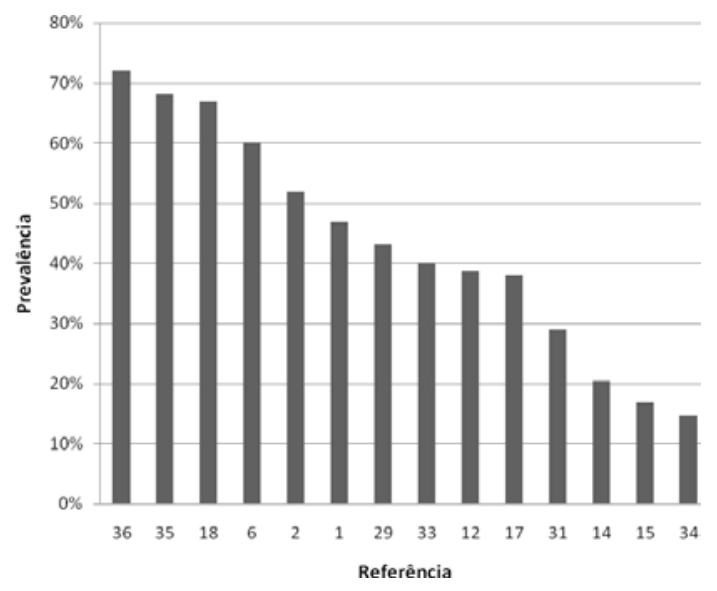

Fig.1 Symptoms Prevalence to low back pain

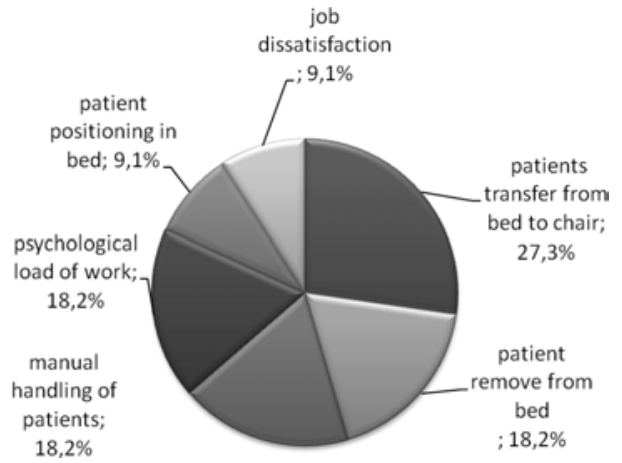

Fig.2 Injuries causes to low back pain to nursing

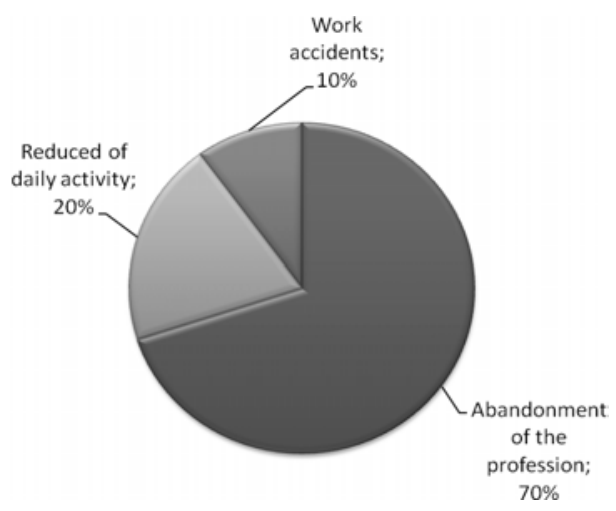

Fig.3 Injuries consequencie to low back pain to nursing

\section{Conclusion}

It was possible to conclude that the prevalence of low back injury is high among nursing professionals and its causes are related to occupational factors - physical or psychological, which are in many cases permanent and disabling.

\section{References}

[1] Dehlin, O. et al. Back symptoms in nursing aides in a geriatric hospital. Scand. J. Rehab. Med. 1976; (8): 47-53.

[2] Harber, P. et al. Occupational low-back pain in hospital nurses. J. Occup. Med. 1985; v.27 (7): 518-24.

[3] Cavassa C.R. Ergonomia y productividad. Limsa Noriega. 1997: 415.

[4] Smedley, J, P Egger, C Cooper, et al. Manual handling activities and risk of low back pain in nurses. Occupational and Environmental Medicine 1995;52:160-163.

[5] Organización Mundial de Salúd - OMS. Identificación de enfermedades relacionadas con el trabajo y medidas para combatirlas. Ginebra: OMS; [editorial] 1985: 31-6.

[6] Sampaio, R. F; Mancini, M. C. Estudos de revisão sistemáticas: um guia para sínte4se criteriosa da evidência científica. Rev. Bras. Fisioter. v. 11, n. 1, p. 83-89, jan./fev. 2007. 